\title{
Effect of a health education program on puberty knowledge among visually impaired female adolescent students
}

\author{
Roza Bahari ${ }^{1}$, Farkhondeh Amin Shokravi ${ }^{1 *} \mathbb{D}$, Monireh Anosheh ${ }^{1}$, Maryam Moridi ${ }^{2}$ \\ Received: 24 Sep 2019 \\ Published: 9 Jun 2021
}

\section{Abstract}

Background: One of the most important aspects of life is reproductive health, which receives less attention in public policy considerations because of its sociopolitical sensitivities. The aim of this study was to evaluate the effect of a designed health education program on knowledge about puberty health among visually impaired female adolescent students during 2011 and 2015.

Methods: This quasi-experimental study was conducted on 100 visually impaired female students aged 10 to 19 years. Data collection tool was a researcher-made questionnaire. Participants were recruited using convenience sampling method from Narjes educational center in Tehran. The educational needs assessments survey was used to learn about important issues and problems faced by this group to design effective educational programs. The effectiveness of the designed program was assessed by comparing the students' knowledge at the baseline and at 1-month follow-up. Data were analyzed in SPSS V.21 by using parametric descriptive statistics. The significant level was set as $\mathrm{p}<0.05$

Results: The results showed that the puberty knowledge of participants was increased in all educational domains after intervention compared to the baseline $(\mathrm{p}<0.05)$. The knowledge about the onset of puberty changes showed the highest increase (from 2.02 at baseline to 7.51 at follow-up) and the knowledge about personal hygiene had the least change after the intervention (from 6.67 to 8.23). The majority of students did not have any information resources regarding puberty health, and about one quarter of them reported their mother as the main resource of puberty information.

Conclusion: Providing educational programs during puberty has a crucial role in young girls' knowledge increase. Providing a continuous health educational program that is tailored to the needs of this group of students using suitablle strategies is recommended.

Keywords: Puberty, Health Education, Blindness, Visually Impaired, Adolescent, Women's Health

Conflicts of Interest: None declared

Funding: Tarbiat Modares University

*This work has been published under CC BY-NC-SA 1.0 license.

Copyright $₫$ Iran University of Medical Sciences

Cite this article as: Bahari R, Amin Shokravi F, Anosheh M, Moridi M. Effect of a health education program on puberty knowledge among visually impaired female adolescent students. Med J Islam Repub Iran. 2021 (9 Jun);35:74. https://doi.org/10.47176/mjiri.35.74

\section{Introduction}

Health is a personal and social value and has been considered as the most significant human right and need in different countries. All nations pay attention to all different groups of the society to obtain the highest level of

Corresponding author: Dr Farkhondeh Amin Shokravi, aminsh_f@modares.ac.ir

1. Department of Health Education and Health Promotion, Faculty of Medical Sciences, Tarbiat Modares University, Tehran, Iran

2. Department of Public Health, Medical Sciences Faculty, Azad University, Arak Branch, Arak, Iran health. Among these groups, adolescent girls are of special importance because they are the future mothers and accordingly they would be able to play a key role in the health status of them selves and their community (1).

$\uparrow$ What is "already known" in this topic:

Visually impaired adolescents have several puberty issues, and due to their limited communication with the society, their selfawareness is lower than visually normal adolescents.

\section{$\rightarrow$ What this article adds:}

The evidence confirmed that education about puberty has an important impact on girls' approach regarding changes during puberty and adjustment of health behaviors. Given the findings of the present research, to enhance the knowledge level of female students toward puberty issues, it is highly important to provide them with correct information through counseling and educational programs. 
Adolescence is an important period of life during which several psychological, social, and physical changes happen. The major change which is considered as the turning point of adolescents is puberty (2). In fact, puberty is considered as an underlying period for different stages of life (3). This period of life is highly important in association with health because many health habits of an individual form in this stage of life which has an important influence on health behaviors in adulthood (1).

Visually impaired adolescents have several puberty issues, and due to their limited communication with the society, their self-awareness is lower than that of the visually normal adolescents. A recent evidence from 43 countries indicated that less than $10 \%$ of children and adolescents with disabilities had access to all forms of education (4).

In 2002, The World Health Organization (WHO) reported that the number of visually impaired people was 45 000000 in the world. At present, a person becomes blind every 5 minutes in the world (5). Also, the WHO expressed that $15.3 \%$ of the population has a disability globally. At the end of 2017, the total number of persons with disabilities in the Asian and Pacific was 690 million (4). In Iran, the number of blind adolescents (10-19 y) is estimated to be 6120 and the highest rates of absolute blindness (18.1\%) belong to Tehran province (capital of Iran) (6). The rate of visual impairment in adolescent girls (10$19 \mathrm{y}$ ) in Tehran was $21.1 \%$ of the total visual impaired population of Tehran (7). Given the allocation of the high percentage of young girls' population, the importance of health education is quite important.

Blindness causes major changes in lifestyle and habits of young girls, which may result in problems in physical, psychological and social adjustments. Also, it has a serious effect on girls, the family, and the community (8). Complications and problems of puberty era are easily preventable and health education is the most important and a basic step in preventing and removing problems of this stage (9). Studies have shown that most of parents, educators, and adolescents are not aware of health issues during puberty, whereas youths are faced with many questions due to physical and psychological changes in this period and naturally they have many physical needs that must be answered. In Iran, adolescents received very limited sexual and reproductive health education through the formal school system. Both national and subnational surveys have shown that young Iranians lack basic information on sexual and reproductive health issues and often receive information from sources that may be misleading or inac- curate. Surveys have also shown that both young people and their parents would like more information on these topics to be taught at school $(10,11)$.

Adolescents have the right to obtain information about puberty changes. It is the duty of parents and teachers to provide reasonable and logical responses. Due to shame or lack of knowledge, most of parents cannot talk about puberty and sexual issues with their children; therefore, the present study aimed to evaluate the effect of a health education program tailored to the needs of this group of students on the knowledge about puberty health in Tehran.

\section{Methods}

\section{Study Design and Participants}

This was a quasi-experimental study with pretest and posttest design, which was conducted from 2011 to 2015 in Tehran, capital of Iran. This study consisted of 3 parts: the puberty health needs assiessment; an interventional part, and a measurement part.

This study was conducted in Narjes educational center in Tehran, Iran. This educational center consisted of 100 visually impaired girls, and those who met the inclusion criteria were recruited for the study. Inclusion criteria were as follows: age 10 to 19 years (12); having at least 1 symptom of puberty (based on tanner's puberty scale); complete blindness; no history of psychological disorders; no use of hormones or drugs; the ability to communicate verbally to answer the questions; and the ability to speak Farsi.

\section{Puberty Health Needs Assesisment}

The puberty health needs assessment was conducted using 3 sources of information, including experts' opinion, target group's ideas, and literature review. The main methods for collecting the opinion of experts (health educator professionals and teachers) and the target group were interview and focus group discussion, respectively. Literature review was set out to explore, delineate, and analyze the recent, current, national and international literature in various aspects of the problem. In this phase of the study, the 4 main domains were determined as educational health needs of blind students. These domains, based on their priorities, were physical health, mental health, physical activity, and sexual health, respectively.

\section{Procedures of Intervention}

The education program was designed based on the results from the needs assessment phase. The outlines of the

Table 1. The outlines of the educational intervention

\begin{tabular}{ll}
\hline Domains & \multicolumn{1}{c}{ Subsets } \\
\hline $\begin{array}{l}\text { Physical } \\
\text { health }\end{array}$ & $\begin{array}{l}\text { Meaning of puberty; onset, and signs of puberty; physical, hormonal, and psychological changes; meaning of menstruation; the } \\
\text { normal changes during menstrual period (normal interval, duration, frequency and amount and bleeding), genital hygiene around } \\
\text { menstruation; common disorders of menstruation; pain relief methods during menstruation; the definition of premenstrual syn- } \\
\text { drome (PMS); physical and emotional changes of PMS; cultural and religious beliefs. }\end{array}$ \\
Mental health & $\begin{array}{l}\text { Association of menstrual cycle related symptoms with changes in mood, Sexual Desire and behavior, anxiety and depression. } \\
\text { Nutrition }\end{array}$ \\
The advantages of good nutrition before and during puberty; diseases caused by inappropriate nutrition; introduce the micro- and \\
macro-nutrients and the role of them in puberty health.
\end{tabular}


educational intervention were shown in Table 1. The intervention program included 4 sessions. Each session was held for 120 to 180 minutes for theory and practice. The educational method for theory issues was lecture and for educating the anatomy of genital system, a moulage was used. Students were trained with a moulage to simulate the anatomical regions (13). Each session was held with 1 student in a private room of the school. The first author conducted the program every Saturday from 9 AM to 12 noon.

\section{Measures}

The data collection tool was a questionnaire, which was consisted of 2 parts: The first part was focused on sociodemographic and obstetric characteristics such as age, educational level, parent's educational level, parent's occupation status, custody status, and menstruation history (date of the last menstrual period, menarche age, duration, and interval of cycle).

The second part of the questionnaire deals with the knowledge of the puberty health assessment. The knowledge of the Puberty Health questionnaire, which was developed by researchers from the need assessment part, was used to assess the effect of educational program before and after intervention. The questionnaire consists of 51 items in 4 domains: physical health (25 items), mental health (19 items), physical activity (4 items), and sexual health (3 items). Each item was checked as (I know) or (I do not know).

The reliability of the questionnaire was assessed by using the test-retest method. The questionnaire was filled out with 50 pilot samples of the visually impaired students twice over 2 weeks. The correlation coefficient of the questionnaire was 0.85, and the Cronbach's alpha was calculated at 0.97 , which indicated a good reliability. For assessing the validity of the questionnaire, an expert panel of specialists in health education and promotion was asked to comment independently on the necessity, relevancy, clarity, and simplicity of the items, and the results suggested a good content validity.

\section{Assessment Phase}

The pretest was implemented to identify the students' knowledge of puberty health. First, the enrolled students were given a description of the study and requirements for participation; next, informed consent was obtained. A total of 100 visually impaired girls were interviewed individually by the first author to fill out the questionnaires.

\section{Evaluation Phase}

To evaluate the effect of the health educational program on the students' knowledge about puberty health, a posttest similar to the pretest was applied 1 month after the intervention.

\section{Statistical Analysis}

Data collected from the questionnaire were coded, entered into statistics package for social sciences (SPSS, version 21.0, Chicago, IL) and tested for normality. Para- metric descriptive statistics were used to analyze the demographic and obstetric data. Paired t test (in bivariate data) was used to determine the effect of education on pubertal knowledge. To categorize puberty health knowledge in each domain, the criterion of median was used; those with a score below 50th percentile were defined as having undesirable knowledge, and those with a score above it as having desirable knowledge. In all statistical analyses, the significant level was set as $\mathrm{p}<0.05$.

\section{Ethical Consideration}

This study was approved by the ethics committee of the Research Deputy at Tarbiat Modares University (IRB code $=1082965$ ). A description of the study and requirements for participation was given to all enrolled women, and informed consent was obtained, where detailed information was offered about the research, and confidentially was assured.

\section{Results}

Sociodemographic and Obstetric Characteristics

We conducted interviews and collected information for

\begin{tabular}{|c|c|c|}
\hline Students' demographics & No. & $\%$ \\
\hline \multicolumn{3}{|l|}{ Age / years } \\
\hline$<15$ & 52 & 52 \\
\hline$\geq 15$ & 48 & 48 \\
\hline \multicolumn{3}{|l|}{ Mother education } \\
\hline Illiterate & 10 & 10 \\
\hline Primary and secondary & 28 & 28 \\
\hline High & 50 & 50 \\
\hline university & 12 & 15 \\
\hline \multicolumn{3}{|l|}{ Father education } \\
\hline Illiterate & 8 & 8 \\
\hline Primary and secondary & 20 & 20 \\
\hline High & 44 & 44 \\
\hline University & 26 & 26 \\
\hline \multicolumn{3}{|l|}{ Mather's job } \\
\hline Housewife & 54 & 55 \\
\hline Self-employed & 8 & 8 \\
\hline Governmental employee & 36 & 36 \\
\hline \multicolumn{3}{|l|}{ Father's job } \\
\hline Unemployed & 6 & 6 \\
\hline Worker & 22 & 22 \\
\hline Self-employed & 40 & 40 \\
\hline Governmental employee & 32 & 32 \\
\hline \multicolumn{3}{|l|}{ Custody Status } \\
\hline Parents & 38 & 38 \\
\hline Single parent & 4 & 4 \\
\hline Father and stepmother & 4 & 4 \\
\hline Mother and stepfather & 4 & 4 \\
\hline Others & 50 & 50 \\
\hline \multicolumn{3}{|l|}{ Menarche age (year) } \\
\hline$\leq 10$ & 26 & 26.5 \\
\hline $11-14$ & 62 & 63.3 \\
\hline$\geq 15$ & 10 & 10.2 \\
\hline \multicolumn{3}{|c|}{ Duration of menstruation (day) } \\
\hline$<5$ & 78 & 79.5 \\
\hline $5-7$ & 18 & 18.3 \\
\hline$>7$ & 2 & 2 \\
\hline \multicolumn{3}{|c|}{ Length of menstruation (day) } \\
\hline$<21$ & 12 & 12.2 \\
\hline $21-35$ & 68 & 69.3 \\
\hline$>35$ & 18 & 18.3 \\
\hline \multicolumn{3}{|l|}{ Amount of bleeding } \\
\hline Light & 22 & 22.4 \\
\hline Medium & 54 & 55.2 \\
\hline Heavy & 22 & 22.4 \\
\hline
\end{tabular}


all of the 100 eligible students enrolled in the study. The mean age of the participants was 12.58 years (range, 11$18 \mathrm{y}$ ). The frequency distribution of the study sample, regarding students' sociodemographic characteristics and menstrual history are listed in Table 2.

\section{Comparison of the Domain Scores Before and After Educational Intervention}

Preprotocol analysis of blind girls' knowledge in the same sample at follow-up was undertaken as the primary assessment of intervention's effectiveness on puberty knowledge $(\mathrm{N}=100)$. Table 3 reported the mean scores of puberty knowledge domains at baseline, follow-up, and the change between baseline and follow-up. As shown, the mean of knowledge in the Physical Hygiene domain had the highest score $(8.23 \pm 0.55)$, and the mean of knowledge in the Signs of Puberty domain obtained the least score (6.14 \pm 3.19$)$, after the intervention.

Changes in scores differed significantly between the pretest and posttest assessment. All domains increased after intervention and the highest change belonged to the Awareness of Onset of Puberty (from 2.02 \pm 2.58 at baseline to $7.51 \pm 2.55$ at follow-up). The Physical Hygiene domain had the highest score before and after the intervention, and its change gained the least score (from $6.67 \pm 0.58$ at baseline to $8.23 \pm 0.55$ at follow-up).

Intervention effectiveness was then compared between the 2 conditions. As shown in Figure 1, the desirable knowledge in each domain after the intervention increased compared to before the intervention.

\section{Discussion}

The aim of the present study was to evaluate the effect of an educational program on the knowledge of visually impaired students. According to students' demographic characteristics, the mean age at menarche was 11.58 years, which is lower than that of girls with normal vision (12.8 $y)$ in Iran (11). There is considerable evidence of a relationship between light exposure and the pituitary-gonadal function in certain animals and humans, which confirm the finding of this study. The lack of light stimulus in these girls induces increase in plasma melatonin concentrations with a free-running rhythm of secretion, which impairs the hormonal secretions of pituitary-gonadal axis, causing disorders of reproductive processes (14-17). Also, age at menarche is influenced by biological and social factors, nutritional status, geographic location, and lifestyle, and it cannot be attributed to a specific factor (11, 18). Regarding parents' education, about one quarter of the fathers and one fifth of the mothers had a university degree, and more than half of the fathers and mothers were self-employed and housewives, respectively. These findings are in line with Frieden (2008) and Abd-El Sattar Ali (2015) who revealed that the highest prevalence of parents of visually impaired girls were found among those parents with low educational level, and due to their low socioeconomic status, only one fifth of the parents completed their university education $(8,19)$. Also, Mongomery and Morris (2011) reported that, the majority of students' mothers

Table 3. The means scores of puberty knowledge domains at baseline, follow-up and change score $(\mathrm{n}=100)$

\begin{tabular}{|c|c|c|c|c|}
\hline Educational domains & $\begin{array}{c}\text { Baselines } \\
\text { M (SD) }\end{array}$ & $\begin{array}{c}\text { Follow-up } \\
\mathrm{M}(\mathrm{SD})\end{array}$ & Change & P-value \\
\hline Signs of puberty & $1.82(1.99)$ & $6.14(3.19)$ & 4.32 & 0.002 \\
\hline Onset of puberty & $2.02(2.58)$ & $7.51(2.55)$ & 5.49 & $<0.001$ \\
\hline Physical changes & $2.47(2.63)$ & $7.81(1.81)$ & 5.34 & $<0.001$ \\
\hline Physical hygiene & $6.67(0.58)$ & $8.23(0.55)$ & 1.56 & $<0.001$ \\
\hline Psychological changes & $3.31(3.13)$ & $8.15(1.41)$ & 4.84 & $<0.001$ \\
\hline Sexual health & $3.99(3.19)$ & $7.06(2.53)$ & 3.07 & 0.019 \\
\hline Physical activity & $2.44(3.39)$ & $7.89(1.79)$ & 5.45 & $<0.001$ \\
\hline
\end{tabular}

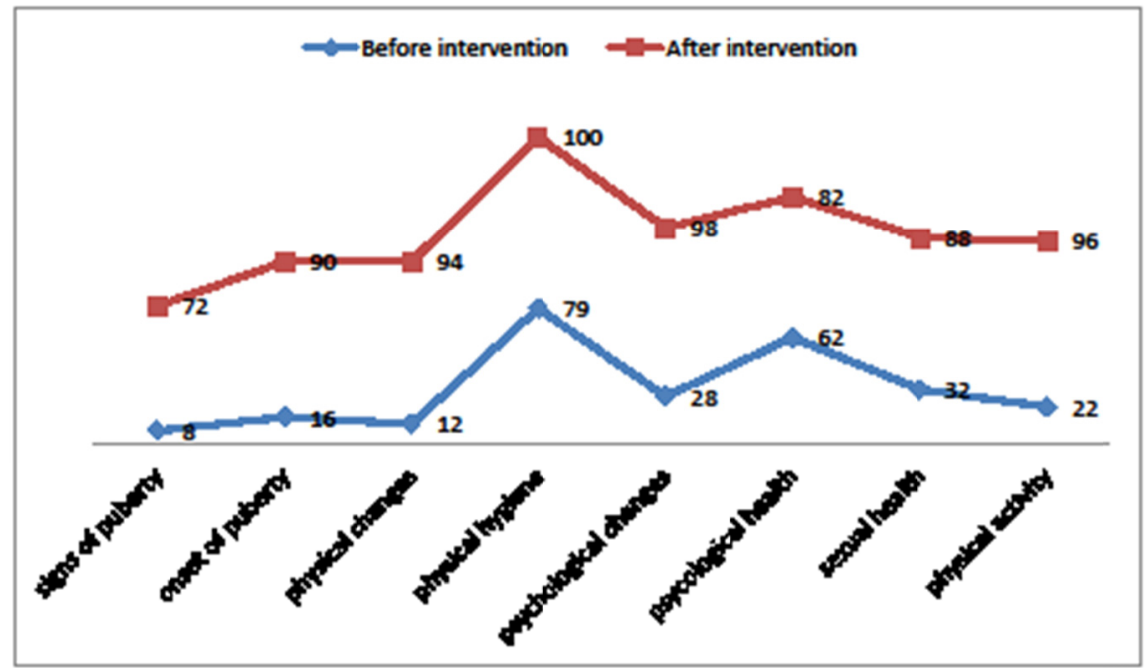

Fig. 1. Comparison of the percentge of desirable knowlegde in each domains 
were illiterate (20).

Based on the obtained results, the knowledge level in all domains before educational intervention was undesirable in about two thirds of the participants, which is consistent with results of other studies conducted both inside and outside Iran $(21,22)$. Hagikhani Golchin NA (2012) in a qualitative content analysis in Iran concluded that anxiety and shame about physical appearance and psychological changes during puberty were the important concerns of Iranian adolescent girls, and most of them were in the need of education regarding how to address issues surrounding puberty (22).

In the present study, the educational needs during puberty were prioritized as physical health, psychological health, physical activity, sexual health, and nutrition. According to the source of students' information, the current study revealed that more than one third of the students had no source of information. One quarter of students considered their mother as their main source of information about puberty, and teachers and friends, respectively, had less roles in this regard. This may explain that visually impaired students had closed social relations only with friends in the institute, their families, and teachers. Also, a study from Iran showed that one of the most important experiences of adolescents to gain information regarding reproductive health was the modesty shown about these issues. The adolescents are ashamed to ask for information from adults who are unwilling to debate these issues. Hence, taboos, beliefs, and traditions may prevent the adolescents from accessing the necessary information (23). In many cultures, parents do not talk about sex with their children. A research revealed that with an increase in the parent-adolescent communication and conversation, the level of reproductive health risk decreases. In addition, some studies revealed that media have a profound impact on young people's knowledge, beliefs, and attitudes related to reproductive health (24). This resource transfer limited proper information in this regard due to cultural and religious context of Iran. Therefore, it is essential to provide access to reproductive health information and government services to adolescents.

The research findings showed that teaching puberty issues to visually impaired students could increase their knowledge about puberty and menstruation. This result is in accordance with Abd-El Sattar (2015) who stated that blind adolescent students' knowledge regarding nutrition, personal hygiene, exercise, follow-up, sleep, reproductive health, and psychological health improved after implanting the puberty educational program (8). Many studies, which were done on normal vision adolescent girls, also indicated the impact of education on increased level of knowledge regarding puberty health $(10,25)$. Mehrabi et al (2016) showed that teaching puberty issues to firstgrade high school students can increase their knowledge about puberty and menstruation (10). Afghari et al (2008) also proved that puberty health education both affects the adolescents' knowledge and improves their healthy behavior (26).

Based on the results of the present study, the maximum score was seen in physical hygiene, which remained the highest score in the posttest assessment and the least change in this score was observed. Regarding the main reason for this result, generally in Iranian cultural and religious context, Muslim people pay a lot of attention to physical and personal hygiene. In addition, an important part of Islamic religious teaching is about such issues. Another possible reason is that all participants were selected from an educational institute where the health education sessions are held for all students as a part of educational curriculum. These sessions mainly focused on issues related to public and personal health and hygiene.

In puberty period, to remove the health risks for adolescents, their knowledge should be increased. Knowledge and awareness of girls from observing health tips during puberty can have an effective role in their performance and can decrease many subsequent problems for them. Due to shame and modesty, young girls usually do not speak about problems of puberty era with their mothers; and education is the most effective goal for changing behavior and young girls need knowledge and life skills to make a right decisions in life. Some studies suggest that practical training, individually or in small groups, has had the greatest success in children's safe behavior progression (27). Generally, almost all the educational interventions in many different areas (Darabi (28); Amin Shoukravi (29); gholannia (30); and Najarkolaei (31)) have shown a significant effect on the promotion of the studied topic after the intervention when the target group was younger than 13 years.

The strength of our study was the method of the educational program design, which was based on the real needs of the visually impaired Iranian girls. The main limitation of the present study was the self-report method of completing the questionnaire that could cause overestimation or underestimation of the results, limiting the result of the study. In addition, psychological differences were not controllable in this study; thus, it is recommended that further studies take into account measures to assess the effect of psychological factors on the learning process in health education.

\section{Conclusion}

The evidence confirmed that education about puberty has an important impact on the girls' approach regarding changes during puberty and adjustment of health behaviors. Given the findings of the present research, to enhance the knowledge level of female students toward puberty issues, it is essential to provide correct information to this group through counseling and educational programs. Accordingly, the Eastern Mediterranean Health Organization stated that continuous health education to adolescents through schools and health services of schools for preventive health care in the first and second levels should be done for all the students as weil as for maternal and child health. Given the role of health education in promoting knowledge level, which can change behavior and improve performance, it is suggested to put educational program in the agenda of health promotion programs based on the needs of different groups, particularly visually impaired girls due to their limited social communication. 


\section{Acknowledgment}

Authors highly the help and support of Narjes educational center as well as the school principals, teachers, students, and authorities who helped us in this project. This article was approved in the research committee of Tarbiat Modares University (code: 108923) in May 2014.

\section{Conflict of Interests}

The authors declare that they have no competing interests.

\section{References}

1. Moodi M, Zamanipour N, Sharifirad GR, Shahnazi H. Evaluating puberty health program effect on knowledge increase among female intermediate and high school students in Birjand, Iran. J Educ Health Promot. 2013 Oct 30;2:57.

2. Edelman C, Kudzma E. Health Promotion Throughout the Life Span. 9th ed. China: Elsevier; 2017.

3. Lackovic-Grgin K, Dekovic M, Opacic G. Pubertal status, interaction with significant others, and self-esteem of adolescent girls. Adolescence. 1994;29(115):691-700.

4. Economic and Social Commission for Asia and the Pacific (ESCAP). Building Disability-Inclusive Societies in Asia and the Pacific: Assessing Progress of the Incheon Strategy [Internet]. Thailand: United Nations Publication; 2018 [cited 2018 Jan 3]. Available from: https:/www.unescap.org/publications/building-disability $\% \mathrm{E} 2 \% 80 \%$ 91 inclusive-societies-asia-and-pacific-assessing-progress-incheon.

5. Fathizadeh N, Takfallah L, Badrali N, Shiran E, Esfahani MS, Akhavan H. Experiences of blind children caregivers. Iran J Nurs Midwifery Res. 2012;17:S143-S149.

6. Eftekhar H, Nojoomi M, Koohpayeh-Zadeh J. A Comparison of the Quality of Life Among Blind Students and Their Sighted Counterparts. Iran J Psychiatry Clin Psychol. 2002;7(4):49-55.

7. Soori H, Ali JM, Nasrin R. Prevalence and causes of low vision and blindness in Tehran Province, Iran. J Pak Med Assoc. 2011 Jun;61(6):544-9.

8. Abd-El Sattar Ali R, Mohamed Abd-El Aal E. Effect of Health Educational Program for Females Blinded Adolescents Students Regarding Reproductive Health. Am J Nurs Sci. 2015;4(1):1-8.

9.EB. K. Women's perceptions of the adolescent experience. Adolescence. 1997;32(127):715-34.

10. Mehrabi S, Etemadi A, Borjali A, Sadipoor E. The Effect of Puberty Education on Knowledge, Attitude and Function of Girl's Students. Patient Saf Qual Improve J. 2016;4(3):405-9.

11. Bahrami N, Soleimani MA, Chan YH, Ghojazadeh M, Mirmiran P. Menarche age in Iran: A meta-analysis. Iran J Nurs Midwif Res. 2014;19(5):444-50.

12. World Health Organization. Adolescent health. . Maternal, newborn, child and adolescent health. 2019. Available on: https://www.who.int/maternal_child_adolescent/adolescence/en/

13. Stokes-Parish J, Duvivier R, Jolly B. Expert opinions on the authenticity of moulage in simulation: a Delphi study. Adv Simul (Lond). 2019;4(16):1-10.

14. Bellastella A, De Bellis A, Bellastella G, Esposito K. Opposite influence of light and blindness on pituitary-gonadal function. Front Endocrinol (Lausanne). 2014;4:205

15. Lehrer S. Fertility of blind women. Fertility and sterility. 1982;38(6):751-2.

16. Zacharias L, Wurtman RJ. Blindness: its relation to age of menarche. Science. 1964 May 29;144(3622):1154-5.

17. Sellix MT. Clocks Underneath: The Role of Peripheral Clocks in the Timing of Female Reproductive Physiology. Front Endocrinol (Lausanne). 2013;4:91.

18. Karapanou O, Papadimitriou A. Determinants of menarche. Reprod Biol Endocrinol. 2010;8:115.

19. Frieden TR, Bassett MT, Thorpe LE, Farley TA. Public health in New York City, 2002-2007: confronting epidemics of the modern era. Int J Epidemiol. 2008 Oct;37(5):966-77.

20. Montgomery B, L. M. Surviving: Coping with life crisis. 5th ed. London: Lippincott Williams \& Wikins; 2011.

21. Uskul AK. Women's menarche stories from a multicultural sample. Soc Sci Med. 2004 Aug;59(4):667-79.
22. Golchin NAH, Hamzehgardeshi Z, Fakhri M, Hamzehgardeshi L The experience of puberty in Iranian adolescent girls: a qualitative content analysis. BMC Public Health. 2012 Aug 27;12:698.

23. Yari F, Moghadam ZB, Parvizi S, Nayeri ND, Rezaei E. Sexual and reproductive health problems of female university students in Iran: a qualitative study. Glob J Health Sci. 2015 Jan 14;7(4):278-85.

24. Kalembo F. W, Zgambo M DY. Effective Adolescent Sexual and Reproductive Health Education Programs in Sub-Saharan Africa. Calif J Health Promot. 2013;11(2):32-43.

25. Marvan ML, Alcala-Herrera V.. Age at menarche, reactions to menarche and attitudes towards menstruation among Mexican adolescent girls. J Pediatr Adolesc Gynecol. 2014;27(2):61-6.

26. Afghari A, Eghtedari S, Pashmil R, Hossein Sadri G. Effects of puberty health education on 10-14 year-old girls' knowledge, attitude, and behavior. Iran J Nurs Midwif Res. 2008;13(1):38-41.

27. Thomson JA, Ampofo-Boateng K, Lee DN, Grieve R, Pitcairn TK, Demetre JD. The effectiveness of parents in promoting the development of road crossing skills in young children. $\mathrm{Br}$ J Educ Psychol. 2011;68(4):475-91.

28. Darabi L, Amin Shokravi F, Ghaffari M. Comparison of Two Methods of Direct and Indirect Education on Osteoporosis Preventive Behaviors among Female Students. Int J Pediatr. 2017;5(8):5483-92.

29. Amin Shokravi F, Hakim Shooshtari M, Shahhatami H. The Impact of a Sleep Hygiene Intervention on Sleep Habits in Children with Attention Deficit/Hyperactivity Disorder. Int J Pediatr. 2016;4(12):4117-26.

30. Gholamnia Shirvani Z, Amin Sholkravi F, Ardestani MS. Evaluation of a health education program for head lice infestation in female primary school students in Chabahar City, Iran. Arch Iran Med. 2013 Jan;16(1):42-5.

31. Najarkolaei FR, Niknami S, Aminshokravi F, Tavafian SS, Joneidi Jafari NA, Golabchi A. Promoting sexual abstinence intention among female university students: A quasi-experimental study. J Res Med Sci. 2013;18(1):37-43. 